\title{
Measuring Job Satisfaction Level of Government Sector Employees: A case of Bureau of Statistics, Government of Sindh, Pakistan
}

\author{
Shah Nawaz Jiskani \\ Institute of Business \& Technology (Biztek) \\ Khalili-ur-Rehman Bhatti \\ University of Sindh, LAAR Campus, Badin \\ Shoaib Ahmed \\ IQRA University, Karachi
}

\begin{abstract}
Purpose-This study examines level of job satisfaction among the staff of Sindh Bureau of Statistics, Planning \& Development Department, Government of Sindh.

Methodology/Sample- The Bureau was randomly selected amongst the nonSecretariat departments which mostly have grievances developed against the policies discriminating in favour of the Secretariat employees and in disfavor of the subsidiary departments and bureaus. The study was based on measurement of satisfaction of employee satisfaction against various facets of their job. A random sample of 40 out of 100 staff members (from BPS-5 to BPS-18) was selected for investigation. Using exploratory research approach, close-ended questionnaire was used with four-point Likert scale. Background conservation and chats were also held with the sample members especially where they needed clarification.

Findings- These conservations provided a healthy insight to the authors into the matter. Job facets like job security, immediate supervisors behavior, recognition, interpersonal relations, workload, career growth and pay/compensation were the factors that the employees showed satisfaction with. Whereas working conditions, feelings of achievement and government policies turned out to be the dissatisfying factors.

Practical Implications- Findings of the study are likely to offer guideline to other government departments in understanding the various job satisfaction facets in the government sector departments and taking measures in that regard.
\end{abstract}

Keywords : Job satisfaction, Job dissatisfaction productivity, immediate supervisor behavior working conditions

\section{Jel classification : E230}

\footnotetext{
* The material presented by the author does not necessarily portray the viewpoint of the editors and the management of the Institute of Business \& Technology (Biztek) or IQRA University and University of Sindh, LAAR Campus.

* Shah Nawaz Jiskani : snjiskani@gmail.com

* Khalili-ur-Rehman Bhatti : bhattikrb@yahoo.com

* Shoaib Ahmed: ah.shuaib@gmail.com

(C) JMSS is published by the Institute of Business and Technology (Biztek). Main Ibrahim Hydri Road, Korangi Creek, Karachi-75190, Pakistan.
} 
Measuring Job Satisfaction Level of Government Sector Employees: A case of Bureau of Statistics, Government of Sindh, Pakistan

\section{INTRODUCTION}

Empirical studies support this idea that satisfied employees mostly perform well (Hunter $\&$ Tietyen, 1997). Elton Mayo was among the pioneers who worked over various dimensions of job satisfaction and found that the workers' perceptions about management attitude and behavior left an impact on their productivity (Pugh, 1990). Subsequently, getting inspired by the findings of Elton Mayo's work, Frederick Herzberg explored the new dimensions propounding that employees express their dissatisfaction with job security, pay or policies. Secure job, reasonable salary package and evidence based policies and decision making does not necessary mean to have satisfied employees, hygiene factors like recognition, achievement and growth are also significant regarding employee satisfaction and might be supportive to increase job pleasure level.

Davis and Newstrom (1999) see job satisfaction as an experience with multiple facets. To them, the factors that are relevant to working conditions and the nature of work are also significant. They believe that lack of job autonomy, lack of job security, low salaries and slow promotions adversely affect job satisfaction of employees. Berry (1997) describes job satisfaction as an individual's reaction to the work experience. It is selfevident that human resource practitioners are struggling for improving job satisfaction among the workforce and it has received significant attention of researchers and managers. Subscribing to the argument of Berry, Organ and Ryan (1995) say that better interpretation of job satisfaction and influencing factors can support managers to motivate the employees for higher performance.

Keeping in view the significance, impact and contribution of job satisfaction towards productivity as it is evident from these studies, it can be asserted that the topic of job satisfaction has received a great deal of different stakeholders' attention. Same is the case with the organization under study i.e. Bureau of Statistics, Government of Sindh, Pakistan. The Bureau was randomly selected amongst the non-Secretariat departments which mostly have grievances developed against the policies discriminating in favour of the Secretariat employees and in disfavor of the subsidiary departments and bureaus. It was noted that employees of the Bureau were getting themselves transferred to other departments on deputation basis reflecting that reflected reduced job satisfaction level among the employees. Hence, this study.

\subsection{Research Hypotheses}

$\mathrm{H}_{1}$ : There exists perceived job insecurity among the employees of BOS.

$\mathrm{H}_{2}$ : The Bureau employees are dissatisfied with the opportunities for advancement and career growth available to them.

$\mathrm{H}_{3}$ : $\quad$ Bureau employees are dissatisfied with their on-the-job and career related achievements

$\mathrm{H}_{4}$ : Bureau employees are dissatisfied with the supervisory practices at their workplace.

$\mathrm{H}_{5}$ : Bureau employees are dissatisfied with the level of recognition of their achievements.

$\mathrm{H}_{6}$ : The Bureau employees are experiencing poor interpersonal relations which is a source of dissatisfaction on the job among them

$\mathrm{H}_{7}$ : $\quad$ BOS employees are dissatisfied with their pay.

$\mathrm{H}_{8}$ : $\quad$ BOS employees are dissatisfied with their perceived work overload.

$\mathrm{H}_{9}$ : $\quad$ BOS employees are dissatisfied with their working conditions

$\mathrm{H}_{10}$ : BOS employees are dissatisfied with the Government/Departmental policies.

\section{LITERATURE REVIEW}

Spector (1997) and Kreitner \& Kinicki (2006) described job satisfaction as a universal concept or as a group of diverse dimensions to which the workers respond affectively. 
Furthermore, Spector (1997) infers that it has become an attitudinal variable after large amount of research on job satisfaction in last 30 years. Dawes (2004) defined job satisfaction as a psychological construct by as having two constituents: a cognitive component (the perception that one's needs are being fulfilled), and an affective component (the feeling that accompanies the cognition). Adana (1986) says a rewarding occupation or job is the most consistent means of gaining the essential paybacks, rights and fulfillments in the society. These paybacks include monetary, safety, social status, personal and social privileges, medical facilities, entertainment and learning openings etc.

Ghosh (1972) is of the view that job satisfaction is a combination and collection of positive and negative sentiments and feelings with which staff perceive their effort. It is the way the employees perceive about the various job-related variables like workload, sense of reliability and job security, job characteristics, level of control over procedures, task responsibilities, transport facilities, relations with supervisors which is perceived as tool work-related problems etc. Kreis \& Brockopp (1986) say that job satisfaction is linked to self-perception with respect to achievements of expectations from work or Abraham Maslow's theory of need. Pennington and Riley (1991) say that employees' general appraisal about their job satisfaction is made according to an absolute context, while an employee's evaluation about the satisfaction level with respect to individual factors is based on specific work context and that includes cross-comparison among employees.

As Job satisfaction and motivation are interrelated (Gosh 1972), much of its literature on jib satisfaction has roots in the theories of motivation. Gosh has also stated that despite the volume of research on the subject, what actually causes job satisfaction is yet to identify, hence more reliance on the motivation theories. Accordingly, motivation theories have been cited by most of the researchers to trace the roots of job satisfaction. This study also takes various concepts of motivation into account for the same purpose.

\subsection{Job Satisfaction: Global Perspective}

European countries have practiced job satisfaction theory in shaping their economies and they developed their traditional economies to dynamic knowledge-based economies of the world by focusing on job satisfaction as a key to improving productivity by motivating their employees. European Commission's measurement framework for quality in work includes job satisfaction as one of several indicators. In working conditions or work environment, the concept of job satisfaction is an important factor and its relationship with work related variables and some individual variables have importance.

The empirical findings of Luddy (2005) indicate that government employees in South Africa are most satisfied with the interpersonal relations with their colleagues, followed by the work itself and the relations with supervisor. But they are dissatisfied with career growth, promotions, pay and compensation. Other potential impact on job satisfaction may come from the factors like work timings, workload, fiscal variables, employee welfare, methodology, employment contracts, markets and job flexibility. Tatsuse \& Sekine (2011) explained facets of job satisfaction in Japanese civil servants case study and concluded that job satisfaction related to the intrinsic aspects of the job (i.e., 'interests and skills involved in work' and 'how abilities were used') contributed more to global job satisfaction than the other aspects of job satisfaction. Zhai Qing-guo (2008) examined the effect of demographical variables on global job satisfaction in China's urban workforce and concluded that when demographic variables like, income, and job level are used as predictors of global job satisfaction, the model is not significant.

\subsection{Job Satisfaction: National Perspective}

Certain studies have been conducted in the area of job satisfaction in Pakistan as well. Findings of the Hunjra (2010), for instance, indicate an affirmative relationship between autonomy, leadership behavior and team work environment and job satisfaction. Employee 
Measuring Job Satisfaction Level of Government Sector Employees: A case of Bureau of Statistics, Government of Sindh, Pakistan

satisfaction has positive significant correlations with organizational culture. Ayub and Rafif (2011) examined the relationship between work motivation and job satisfaction and they conclude that work motivation improves job satisfaction. They also found that when employers are caring and supportive and focus attention on motivating factors the outcome is more productive and committed employees.

Danish and Usman (2010) also studied job satisfaction and motivation among organizational employees in Pakistan and their analysis revealed that a close relationship exists between several dimensions of work motivation and satisfaction but recognition along with work itself and policies have revealed low mean values and insignificant relationship. They concluded that in Pakistani context workers do not expect too much acknowledgment from their bosses on better performance. They further concluded that worker's involvement in the decision making could made them more daring and excited towards working and on the other hand the financial benefits i.e. bonuses, salary increments, fringe benefits, allowances, facilities and other compensations on regular and specific intervals retains their determination and higher motivation.

\section{METHOD}

The study is based on simple random sampling technique, containing a sample of 40 employees out of 100 population or total working employees of Bureau from BPS-5 to BPS-18. Descriptive statistics and T- tests have been employed using SPSS 18. Each employee part of the sample was personally approached and served with a close-ended questionnaire to measure influence of 10 factors/variables of job satisfaction on four-point Likert scale. Face to face conservation was also held with the sample members to reply the queries raised by respondents.

\subsection{Results}

As shown in Table 1 below "Job Security, Immediate Boss, Recognition and Work load remained above 3 i.e. more than $75 \%$ showing a sizeable score of respondents' agreement of opinion.

Table 1

\begin{tabular}{|l|r|r|r|r|}
\hline & \multicolumn{1}{|c|}{$\mathrm{N}$} & \multicolumn{1}{c|}{ Mean } & \multicolumn{1}{c|}{ Std. Deviation } & \multicolumn{1}{c|}{ Std. Error Mean } \\
\hline Reliability and security & 40 & 3.2250 & .76753 & .12136 \\
Career Growth and Development & 40 & 2.9500 & .74936 & .11848 \\
Achievement & 40 & 2.6750 & .65584 & .10370 \\
Immediate Boss/supervisor & 40 & 3.1750 & .67511 & .10674 \\
Recognition & 40 & 3.0500 & .59700 & .09439 \\
Interpersonal relation with colleagues & 40 & 2.9500 & .74936 & .11848 \\
Pay & 40 & 2.9250 & .57233 & .09049 \\
Work Load & 40 & 3.1000 & .63246 & .10000 \\
Work condition & 40 & 2.7750 & .69752 & .11029 \\
Government policy & 40 & 2.2000 & .68687 & .10860 \\
\hline
\end{tabular}

Table 2 below contains scientific evidence to accept or refute the set hypothesis established on the basis of P Value. $\mathrm{H} 3$ with $\mathrm{P}$ value 0.003 stands accepted that shows that the employees of BOS are dissatisfied as far as the sense of achievement emanating from their job itself is concerned. P Value of $\mathrm{H} 9$ stands 0.048 that means this hypothesis also stands accepted. This value shows that there exists perceived dissatisfaction of the employees over their work conditions. Finally $\mathrm{P}$ value for $\mathrm{H} 10$ comes to be 0.00 , significant one, making the hypothesis accepted that establishes that there exists a perceived dissatisfaction of the employees over the Govt. Policies. All remaining seven hypotheses with insignificant value stand rejected. 
Table 2

\begin{tabular}{|c|c|c|c|c|c|c|}
\hline & \multicolumn{6}{|c|}{ Test Value $=3$} \\
\hline & \multirow[t]{2}{*}{$\mathrm{T}$} & \multirow[t]{2}{*}{ Df } & \multirow[t]{2}{*}{$\begin{array}{c}\text { Sig. } \\
\text { (2-tailed) }\end{array}$} & \multirow[t]{2}{*}{$\begin{array}{c}\text { Mean } \\
\text { Difference }\end{array}$} & \multicolumn{2}{|c|}{$\begin{array}{l}95 \% \text { Confidence Interval of the } \\
\text { Difference }\end{array}$} \\
\hline & & & & & Lower & Upper \\
\hline Reliability and security & 1.854 & 39 & .071 & .22500 & -0205 & 4705 \\
\hline Career Growth and Development & -422 & 39 & .675 & -.05000 & -2897 & .1897 \\
\hline Achievement & -3.134 & 39 & .003 & -.32500 & -.5347 & -.1153 \\
\hline Immediate Boss/supervisor & 1.639 & 39 & 109 & .17500 & -.0409 & .3909 \\
\hline Recognition & .530 & 39 & .599 & .05000 & -1409 & .2409 \\
\hline $\begin{array}{l}\text { Interpersonal relation with } \\
\text { colleagues }\end{array}$ & -422 & 39 & .675 & -.05000 & -.2897 & .1897 \\
\hline Pay & -829 & 39 & .412 & -.07500 & -2580 & .1080 \\
\hline Work Load & 1.000 & 39 & .323 & 10000 & -1023 & .3023 \\
\hline Work condition & -2.040 & 39 & .048 & -22500 & -4481 & -0019 \\
\hline Government policy & -7.366 & 39 & .000 & -80000 & -1.0197 & -5803 \\
\hline
\end{tabular}

The Graph 1 below portrays an overall picture of respondents' satisfaction standing. The graph shows that Govt. Policies factor is the one the employees feel dissatisfied the most with while other two factors i.e. feelings of achievement and working conditions emerged as medium level satisfiers. Rests of the factors were found to be equal to or greater than $80 \%$ of satisfaction rate and, thus, termed strong satisfiers.

Graph 1:

Respondents' Satisfaction Rate per Each Factor

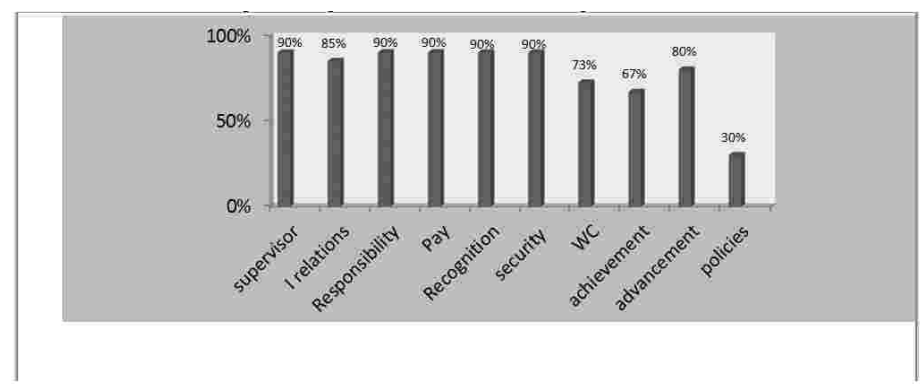

\subsection{Discussion}

Satisfaction intensity for the job security remained 90\%. It means Bureau's employees enjoy long term job. Majority of the employees i.e. $90 \%$ are not worried about their job security. However, remaining paltry $10 \%$ are still feeling that BOS employment is not secure. Government's "Removal from Service Ordinance 2000" may be the cause of this $10 \%$ dissatisfaction whereby any Government employee can be removed from the service with a 7 days' notice even without proof of an allegation.

Regarding career advancement opportunities, results show that $80 \%$ of the total sample employees are well satisfied with the career growth and advancement in their jobs, rejecting the $\mathrm{H} 2$. This seems nascent satisfaction resulting from recent large scale promotions in BOS after retirement of employees. Another factor of this satisfaction may be recent wave of restructuring and survey projects in which many employees have been given opportunity of work and earning extra remuneration. However, dissatisfaction among $20 \%$ of the employees in this area reflects frustration among small section of employees perhaps because BOS had a too slow process of promotions as compared to some other government departments over the last one decade. 
Measuring Job Satisfaction Level of Government Sector Employees: A case of Bureau of Statistics, Government of Sindh, Pakistan

On the factor of feelings of achievement, $67 \%$ of the sample employees felt that they had achieved what they had expected from this job while remaining $33 \%$ are not satisfied with the level of their achievement, hence rejecting the $\mathrm{H} 3$ as well. Though percentage of satisfied employees in this factor is higher than dissatisfied but $33 \%$ percent and 2-tailed t-test result reject the hypothesis. It can be easily concluded that $33 \%$ of the sample employees perceive they do not meet their expectations from this job. Majority of respondents are reaching superannuation and when they compare output of their long service with the BOS with those from Planning \& Development Department or those from private sector organizations, these employees feel themselves at lower position.

$90 \%$ of the sample employees expressed satisfaction with the supervisory style and practices. This high rate of satisfaction with the supervisory practices may be due to permanent nature of the job, better interpersonal relationships and internal departmental mores of BOS. Previous studies indicate that in Pakistani environment employees do not expects a high cooperation from their superiors. So it could be one of the reasons for recording higher satisfaction level in this area.

In the area of recognition for achievements, 90\% employees showed agreement with the level of recognition they were receiving from their seniors. This high level satisfaction in the area of recognition may be due to limited opportunities of work and employees feel that they are free most of time and whenever they found opportunity of work or survey task in the department they performed well and got reward for the assignment.

Regarding interpersonal relations, satisfaction rate remained $85 \%$ that reflects friendly terms among the employees. Observation and background interviews revealed that the BOS employees have together for quite some time. There had been no fresh recruitment for long period and the existing employees had developed stronger interpersonal and inter-family bonds and relations. Dissatisfaction of the $15 \%$ of the sample members can be hardly ignored and seems to have emerged out of perception of favouritism practiced by the senior management whenever any opportunity emerges in the BOS that has been source of soaring inter-personal relations.

In the area of pay and compensation, $90 \%$ of the sample members showed satisfaction with the level of remuneration and salaries they received. Longevity of service may be a source of healthy packages the employees were taking home. Other reason for higher satisfaction rate on this account may be recent spate of survey projects the BOS employees were engaged in and were earned extra remunerations and bonuses. Dissatisfaction among the $10 \%$ of the sample employees on pays and compensations reflects a tinge of frustration among them emanating from favourable treatment to Secretariat employees in the similar areas of compensation. For example, BOS employees are not paid Secretariat allowance, annual bonuses, indoor medical facility and transport facility etc. that is available to the Secretariat employees.

Regarding workload, result shows $90 \%$ sample employees are satisfied with. BOS offices were handed over to district governments in 2001 in result of SLGO 2000 and Statistical activity was almost stopped in field offices. Overall workload in BOS was decreased and subsequently employees feel relax.

Regarding working conditions a good majority of employees ( $72.5 \%$ of the sample) was found satisfied with working conditions and environment but dissatisfied section of the employees $(27.5 \%)$ could hardly be ignored. Background interviews revealed that dissatisfaction may be due to overall environment of bad law and order situation, inflation and natural disasters in the population area. 2-tailed t-test result supports the dissatisfaction factor as its value is less than 0.05 . Office building is in good conditions but not well maintained. Field offices are even in worse condition where employees do not feel comfortable to work in. High temperature and humidity, excessive noise from the adjacent 
thoroughfares, non-availability of drinking water and standby power generator that causes suffocation during power outages, and existence of other health hazards may be the causes of feelings of bad working conditions. Secondly and most importantly, certain field staff members of the BOS like Enumerators and Statistical Assistants are open to risk of life while in the field.

About Government policies, it transpired from the direct interviews with the respondents that they were dissatisfied when it comes to the decision making over BOS by government. The present organization structure is centralized, whereas nature of organization necessitates a participative style of management requiring involvement of field staff in making decisions that affect their life. During data collection, it was also noticed that many policies of Government had been widely put to criticism like deputation policy, recruitment policies, promotions policy, transfer and posting policy etc. A $70 \%$ dissatisfaction rate expressed by the sample employees was alarming.

\section{CONCLUSIONS}

The study significantly reveals that three factors i.e opportunity for achievement, work environment, and Govt. policies are the sources of job dissatisfaction among the employees of BOS. Dissatisfaction on the part of policies has stemmed from centralized decision making or autocratic style of management which most of the employees expect that they are not taken on board in the decisions which exert impact on their jobs. The overall job satisfaction level as evident from overall job satisfaction mean i.e $75 \%$ indicates that on the average the employees of BOS are satisfied with jobs, however the remaining portion i.e $25 \%$ which reflects job dissatisfaction has emanated from the dissatisfying factors as mentioned above. Whereas all other factors included in this study were found to be strong satisfiers.

In the view of the current deteriorating law and order conditions across the province, the employees' morale seems to be knocked down. As a result they perceive the working environment as a whole unfriendly. It is therefore recommended that proper transport facility with adequate security measures be provided to redeem the lost morale of employees so that they can work with peace of mind and reduce job dissatisfaction. In the wake of low sense of achievement witnessed by the employees of BOS it is worth a recommendation that certain job related measures i.e. job enrichment and job rotation which are functions of Human Resource department should be undertaken. It is pertinent to mention here that the present organization structure of BOS is devoid of HR department and which is a miserable condition as for as corporate governance is concerned.

\section{REFERENCES}

1. Adana, B.S. (1986). Job finding. In T. Ipave (Hd.). Education and vocational guidance: Concepts and approaches. Ibadan: Bezekos.

2. Aydin, Bulent (2009), A Research Analysis on Employee Satisfaction in terms of Organizational Culture and Spiritual Leadership, International Journal of Management.

3. Ayub, N. \& Rafif, S. (2011), The Relationship between work motivation and job satisfaction, Pakistan Business Review July 2011

4. Bhatti, K. R, Cheema F. A, Bashir R., Shaikh, H., Nadeem, A. S (2013) Faceted and Overall Job Satisfaction Among University Teachers: A Case Study of Laar Campus, Sindh University, Pakistan, Science Series Data Report Vol. 5, No. 4;Apr 2013

5. Danish R.Q \& Usman A. (2010), Impact of Reward and Recognition on Job Satisfaction and Motivation: An Empirical Study from Pakistan, International Journal of Business and Management, Vol. 5, No. 2

6. Dawes, R. V. (2004). Job satisfaction, in M. Hersen \& J.C. Thomas (Eds.) Comprehensive Handbook of Psychological Assessment, Vol. 4, 470-481. Hoboken, N.J.: John Wiley \& Sons. 
Measuring Job Satisfaction Level of Government Sector Employees: A case of Bureau of Statistics, Government of Sindh, Pakistan

7. Davis K, Newstrom J (1999).Comportamiento Organizaciona (10th Ed). Mexico: McGraw-Hill.

8. Herzberg F, Mausner B and Snyderman. (1995) The Motivation to Work, Transaction Publishers

9. Hunjra , A. I. (2010) Factors effecting job satisfaction of employees in Pakistani banking sector, African Journal of Business Management, Vol. 4(10)

10. Kreis, K., \& Brockopp, D.Y. (1986). Autonomy: A component of teacher job satisfaction. International Journal of Business and Management

11. Kreitner, R., \& Kinicki, A. (2006). Organizational Behavior. New York: McGraw Hill.

12. Luddy, N (2005), Job satisfaction amongst employees at a Public health institution in the Western Cape.

13. Rose, M. (2001) Disparate measures in the workplace...Quantifying overall job satisfaction, Paper presented at the 200, BHPS Research Conference, Colchester, available at: http://www.iser.essex.ac.uk/bhps/2001/docs/pdf/papers/rose.pdf

14. Spector, P.E. (1997), Job satisfaction: Application, assessment, causes, and consequences, Sage, London.

15. Tatsuse T. and Sekine M. (2011), Explaining global job satisfaction by facets of job satisfaction: the Japanese civil servants study. Environ Health. Mar 16(2)

16. Zhai Qing-guo (2008) Job Satisfaction and its Determinants among China's Urban Workforce, IEEExplore Digital Library

17. Excerpts from www.oup.co.uk/pdf/bt/fincham chapter 5 Motivation and Job Satisfaction

18. Excerpt from report European Foundation for the Improvement of Living and Working Conditions, 2007 